\title{
Determination of Pathogenicity of Breast Cancer 1 Gene Variants using the American College of Medical Genetics and Genomics and the Association for Molecular Pathology Guidelines
}

$$
\begin{aligned}
& \text { تقدير إِراضِيَّة المتغيرات الجمينية لمورث سرطان الثدي (1) باستخدام الدلائل }
\end{aligned}
$$

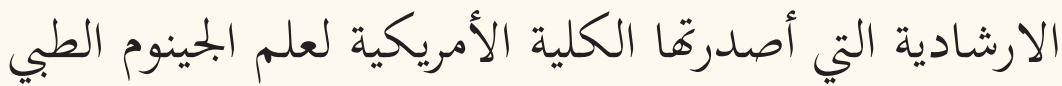

$$
\begin{aligned}
& \text { ومجعية علم الأمراض الجزيئي }
\end{aligned}
$$$$
\text { أنجيلا براون، منصور زمانبور، دونالد لوف، وديبرا بروسر }
$$

\begin{abstract}
Objectives: Molecular diagnostic laboratories screen for mutations in disease-causing genes in order to confirm a clinical diagnosis. The classification of DNA variants as 'pathogenic' or 'likely pathogenic' mutations creates a workflow bottleneck, which becomes increasingly challenging as greater number of genes are screened. The classification challenge is also acute if there are conflicting reports regarding pathogenicity and differing classification criteria between laboratories. This study aimed to compare two procedures for the classification of variants in the breast cancer (BRCA)1 gene. Methods: This bioinformatic study was conducted at LabPLUS, Auckland, New Zealand, from February to June 2017. DNA was extracted from peripheral blood samples of 30 patients and gene library construction was carried out using a commercially available targeted panel for the BRCA1 and $B R C A 2$ genes. The genes were subsequently sequenced and the sequence data analysed. The guidelines published by the American College of Medical Genetics and Genomics and the Association for Molecular Pathology (ACMG/ AMP) provides a comprehensive framework for the interpretation of variants in genes that are associated with Mendelian disorders. The use of these guidelines were compared to the variant classifications that were achieved by reference to those reported in the BRCA Exchange database. Results: The results showed concordance between the two classification protocols for a panel of 30 BRCA1 gene variants, although the transparency in following the ACMG/AMP guidelines provides a diagnostic laboratory with a generalisable approach that allows laboratorydirected revisions to be undertaken in light of new information. Conclusion: The ACMG/AMP-based guidelines were applied to a cohort of patients with $B R C A 1$ gene variants. The use of these guidelines provides a system which creates consistency in variant interpretation and supports subsequent clinical management.
\end{abstract}

Keywords: BRCA1 Gene; Bioinformatics; DNA Sequencing; Nonsense Codon; Splice Donor Site; New Zealand.

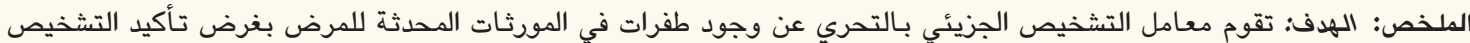

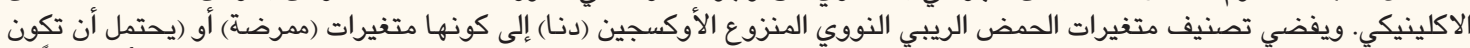

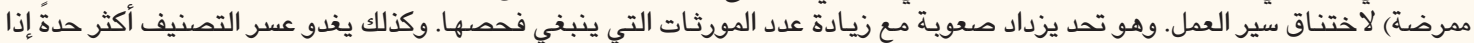

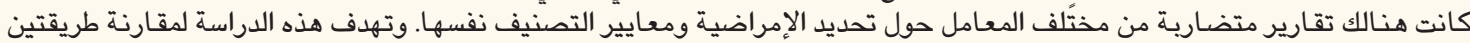

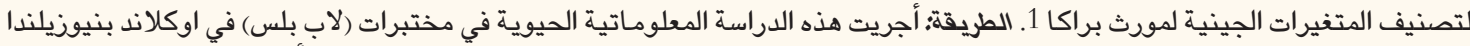

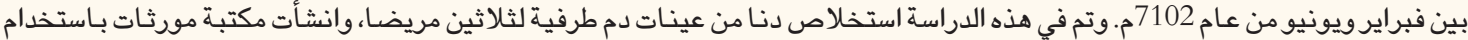

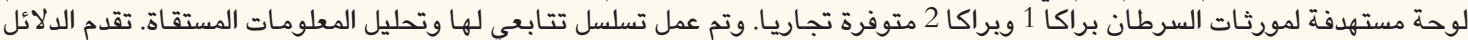

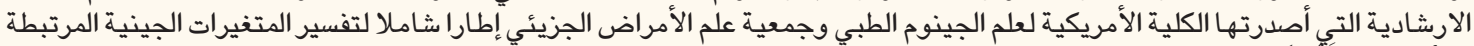

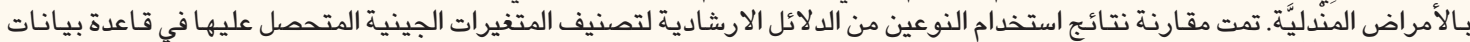

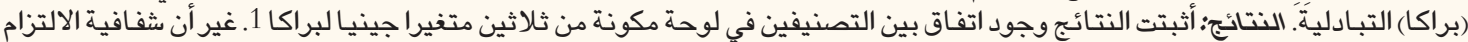

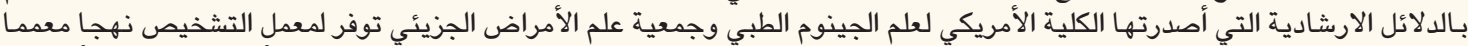

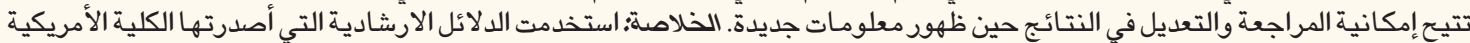

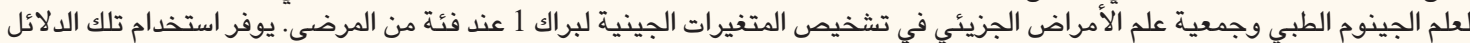

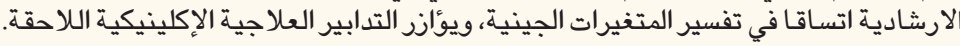

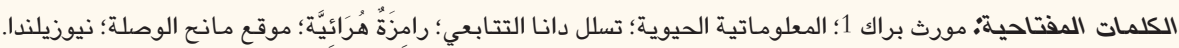


AdVANCES IN KNOWLEDGE

This study reports the use of internationally-accepted criteria for the classification of DNA variants in the context of the breast cancer 1 gene.

\section{Application to Patient Care}

This study emphasises that universally adopted criteria for classifying DNA variants assists in the consistent confirmation of clinical diagnoses and the genetic counselling of family members regarding their risks.

\section{$\mathrm{B}$} REAST CANCER IS THE MOST COMMON malignancy among women, both in developed and developing countries, accounting for one in ten of all new cancers diagnosed worldwide. ${ }^{1}$ Approximately $5 \%$ of breast and ovarian cancers occurs as a result of variants in the breast cancer (BRCA) 1 gene (MIM\# 113705; NM_007294.3; Locus Reference Genomic [LRG]_292), which is localised to the long arm of chromosome 17 at band q21 and comprises 23 exons. Variants within the BRCA1 gene are associated with an 80-90\% lifetime risk of breast cancer. ${ }^{2}$ Patients with pathogenic variants in the $B R C A 1$ gene frequently have a positive family history of breast and ovarian cancer and are often diagnosed at a young age. They may also have a higher incidence of double or multiple primary breast tumours than breast cancer patients in general. ${ }^{3}$ Another gene implicated in breast cancer, BRCA2 (MIM\# 600185; NM_000059.3; LRG_293), is localised to the long arm of chromosome 13 at band q13.1 and comprises 27 exons. ${ }^{4}$ Patients who carry a mutation in the BRCA2 gene have an average risk of $45 \%$ for breast cancer and $11 \%$ for ovarian cancer by the age of 70 years. ${ }^{5}$ There is an elevated risk for prostate cancer in BRCA2 gene carriers and an increased risk of pancreatic, head and neck, stomach and other cancers in patients with a mutation in either of these genes. ${ }^{5}$ Germline pathogenic variants in both the $B R C A 1$ and $B R C A 2$ genes are expressed in an autosomal dominant manner.

Most $B R C A 1$ or $B R C A 2$ gene variants are point mutations or small insertions or deletions. ${ }^{7}$ In $2-12 \%$ of high-risk families, there may be a large genomic rearrangement. ${ }^{5}$ Therefore, it is important to identify patients with disease-causing variants within the $B R C A 1$ or $B R C A 2$ genes as this may enable early treatment options such as surgery, including bilateral prophylactic mastectomy or bilateral prophylactic oophorectomy. The correct classification of variants is paramount in order to avoid invasive outcomes for patients who are not at a high risk of developing cancer. Accurate classification also determines whether predictive testing for other 'at risk' family members would be of value.

Standardisation, in terms of variant classification, is a complex topic characterised by several challenges such as the failure to develop standards, a lack of consensus and incompatible implementation of agreed standards. ${ }^{8}$ These issues should be addressed in order to provide a consistent framework for reporting variants. Identifying a causative variant allows patients and families to be aware of the risks and therefore pursue appropriate management. If the significance of a variant is unknown, then the clinician should decide how to deal with this finding for their patient and the patient's relatives. The heightened uncertainty resulting from a variant of unknown significance can be distressing for patients. ${ }^{9}$ In order to manage and enable consistent and reproducible reporting of these variants, the establishment of universal guidelines is necessary.

To address the need for internationally standardised guidelines for variant nomenclature, a working group was set-up to initiate this process. ${ }^{10,11}$ Currently the responsibility for the maintenance and refinement of these guidelines is carried out by the Human Genome Variation Society (HGVS), and an online tool, termed Mutalyzer, has been developed for laboratories to check the description of sequence variants. ${ }^{12}$

Many online tools have become available to assist in variant interpretation such as ClinVar (www.ncbi. nlm.nih.gov/clinvar/), which aggregates information about genomic variation and its relationship with human health. In addition, the 1000 Genomes Project (www.1000genomes.org) and the Exome Aggregation Consortium (ExAC; http://exac.broadinstitute.org/), the latter being superseded by GnomAD (https:// gnomad.broadinstitute.org/), are useful in obtaining the frequencies of variants in large populations. Diseasespecific databases are also available in order to aid standardisation.

In the case of variants detected in the $B R C A 1 / 2$ genes, useful online resources include the Breast Cancer Information Core (BIC; https://research.nhgri. nih.gov/bic/) and the ENIGMA consortium (http:// enigma.ini.usc.edu/). An ENIGMA member works collaboratively towards the classification of variants and contributes data from families with unclassified sequence variants and/or conducts statistical analysis or laboratory-based assays. Critically, a more global and gene-targeted effort in gathering and collating data, termed the BRCA Challenge, was launched by the Global Alliance for Genomics and Health. As a result of the BRCA Challenge, the BRCA Exchange (https:// 


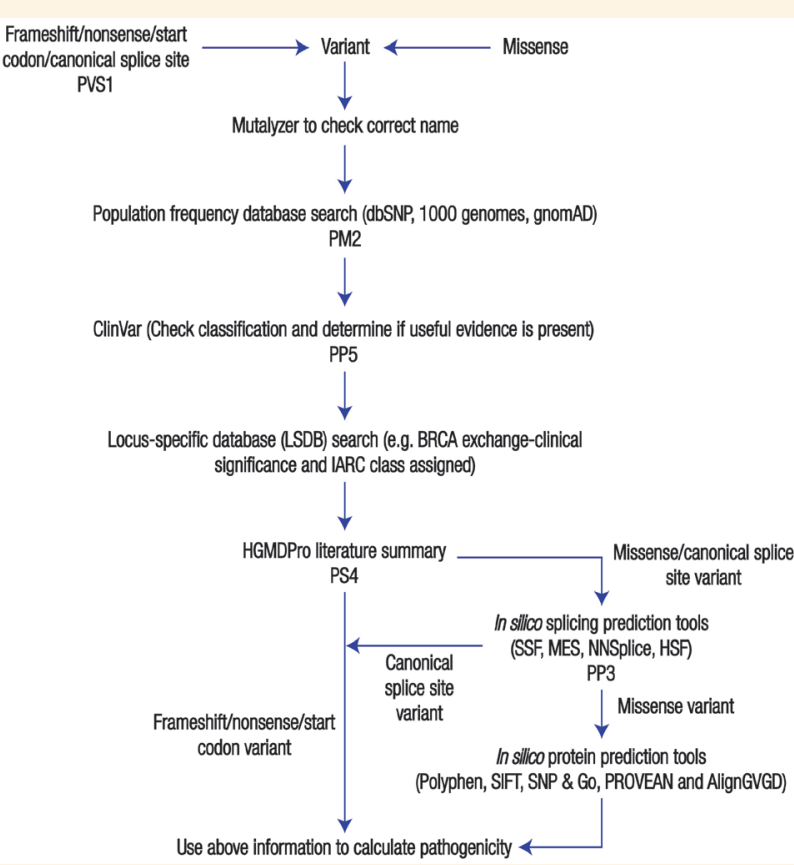

Figure 1: Workflow for classification of variants used in the current study $(\mathrm{N}=30)$.

$P V S=$ very strong evidence of pathogenicity; $P M=$ moderate evidence of pathogenicity; $P P=$ supporting evidence of pathogenicity; $L S D B=$ locusspecific database; $B R C A$ = breast cancer; IARC =International Agency for Research on Cancer; PS = strong evidence of pathogenicity.

brcaexchange.org/) was launched. This initiative combines $B R C A 1 / 2$ genes variant data from many resources such as ClinVar, LOVD (www.lovd.nl/), BIC, ExAC (and GnomAD), 1000 Genomes, ESP (http://evs. gs.washington.edu/EVS), exLOVD and ENIGMA into the world's largest source of non-proprietary BRCA variant-level data, which has enabled the expert review of thousands of variants.

Adding to this gene-specific effort, the American College of Medical Genetics and Genomics and the Association for Molecular Pathology (ACMG/AMP) published standards and guidelines for the interpretation of sequence variants in 2015..$^{13}$ These guidelines describe a framework for classifying Mendelian variants using a list of 28 criteria for determining the impact of a variant. With these guidelines, variants are classified as 'pathogenic', 'likely pathogenic', 'uncertain significance,' 'likely benign' or 'benign'.

In the authors' laboratory, next-generation sequencing (NGS) analysis using targeted BRCA1 and $B R C A 2$ gene panels was validated for diagnostic testing in 2014. The ACMG/AMP guidelines were published and incorporated into testing at the facility as soon as they were published in 2015. This study aimed to classify BRCA1 gene variants according to ACMG/ AMP guidelines and compare the classifications to those reported in the BRCA Exchange.

\section{Methods}

This bioinformatic study was conducted at LabPLUS, Auckland, New Zealand, from February to June 2017. DNA was extracted from peripheral blood samples of 30 patients referred to the Northern hub of the Genetic Health Services New Zealand for BRCA1/2 gene mutation screening. The diagnostic referrals were forwarded for testing based on the Cancer Institute New South Wales guidelines for genetic testing for heritable mutations in the $B R C A 1$ and $B R C A 2$ genes.

Library construction was carried out using the commercially available targeted panel for the $B R C A 1$ and BRCA2 genes from Multiplicom (Agilent Technologies, Inc, The Netherlands). Sequencing was performed using a GS-Junior (Roche Holding AG, Basel, Switzerland) platform. Data analysis was undertaken using JSI SeqNext software (JSI medical systems GmbH, Ettenheim, Germany). In accordance with the AMP and College of American Pathologists NGS validation guidelines, a minimum of 30 reads was considered sufficient for minimum depth of coverage. ${ }^{14}$ If fewer than 30 reads were obtained, Sanger-based sequencing was performed to ensure a reliable result. Analysis included evaluating the coding regions and exon-intron boundaries ( \pm 20 base pairs) of the entire BRCA1 gene. Alamut ${ }^{\circledR}$ Interactive Biosoftware (www.interactivebiosoftware.com/doc/alamut-visual/2.6/splicing.html) 
Table 1: Criteria used in the investigators' laboratory for variant classifications based on American College of Medical Genetics and Genomics and the Association for Molecular Pathology guidelines

\begin{tabular}{|c|c|}
\hline Criteria & Description \\
\hline PVS1 & $\begin{array}{l}\text { Frameshift/nonsense/start codon/splice junction } \pm 2 \\
\text { base pairs/exonic deletion. }\end{array}$ \\
\hline PS1 & $\begin{array}{l}\text { For missense: the same amino acid change at the same } \\
\text { codon is known to be pathogenic (different nucleotide } \\
\text { position). The same amino acid change to be counted } \\
\text { as strong evidence must also, by ACMG definition, be } \\
\text { a class } 5 \text {. If the "other variant" is a class 4, then this evid- } \\
\text { ence become "moderate" rather than "strong" and can } \\
\text { only be used to count as supporting evidence for the } \\
\text { variant of interest to be a class } 4 \text { (likely pathogenic). }\end{array}$ \\
\hline PS2 & $\begin{array}{l}\text { De novo (paternity confirmed) in a patient with the } \\
\text { disease, no family history and phenotype reasonably } \\
\text { specific for the disorder. }\end{array}$ \\
\hline PS3 & Functional study supports damaging effect. \\
\hline PS4 & $\begin{array}{l}\text { Prevalence in affected Pts }>\text { prevalence in controls-OR } \\
\text { is statistically significant. Where a significant number } \\
\text { of cases have been reported carrying the variant and } \\
\text { showed similar phenotype, it can be used as a "moderate" } \\
\text { evidence without OR. }\end{array}$ \\
\hline PM1 & $\begin{array}{l}\text { In mutational hot spot/critical domain (without benign } \\
\text { variations). }\end{array}$ \\
\hline PM2 & $\begin{array}{l}\text { Absent from population databases or extremely low } \\
\text { MAF. Slightly higher is acceptable for recessive } \\
\text { conditions. }\end{array}$ \\
\hline PM3 & For recessive disorders: in trans with known mutation. \\
\hline PM4 & $\begin{array}{l}\text { In-frame insertion/deletion in non-repeat region or } \\
\text { stop-loss variant that results in protein length changes. }\end{array}$ \\
\hline PM5 & $\begin{array}{l}\text { For missense: a known mutation occurs at same codon } \\
\text { (different amino acid residue). The "known" mutation } \\
\text { occurred at the same codon must be either a class } 4 \\
\text { or } 5 \text { by ACMG definition. }\end{array}$ \\
\hline PM6 & $\begin{array}{l}\text { Not present in parents (i.e. assumed de novo) and } \\
\text { phenotype reasonably specific for the disorder (without } \\
\text { confirmation of paternity and maternity). }\end{array}$ \\
\hline PP1 & $\begin{array}{l}\text { Co-segregation with disease (increased weighting } \\
\text { may be applied if stronger evidence available). }\end{array}$ \\
\hline PP2 & $\begin{array}{l}\text { For missense: in this gene missense variants are usually } \\
\text { pathogenic. }\end{array}$ \\
\hline PP3 & $\begin{array}{l}\text { Bioinformatic analysis predicts pathogenic (protein } \\
\text { and/or splice). }\end{array}$ \\
\hline PP4 & Phenotype is highly specific for this single genetic aetiology. \\
\hline PP5 & $\begin{array}{l}\text { A reputable source lists variant as pathogenic but doesn't } \\
\text { state how the classification was determined (reput- } \\
\text { able sources are ClinVar at three or four stars). }\end{array}$ \\
\hline BA1 & MAF $\geq 5 \%$ in any of the population databases. \\
\hline BS1 & Allele frequency above expected for disorder. \\
\hline BS2 & $\begin{array}{l}\text { Found in a healthy individual when full penetrance is } \\
\text { expected at that age (in correct zygosity for disorder). }\end{array}$ \\
\hline BS3 & Functional study supports benign effect. \\
\hline BS4 & Doesn't co-segregate with disease (beware: penetrance). \\
\hline BP1 & $\begin{array}{l}\text { For missense: in this gene missense variants are usually } \\
\text { benign. }\end{array}$ \\
\hline BP2 & $\begin{array}{l}\text { Observed in trans with a pathogenic variant (for domin- } \\
\text { ant inheritance) or in cis with a pathogenic variant (any } \\
\text { inheritance pattern). }\end{array}$ \\
\hline BP3 & $\begin{array}{l}\text { In-frame insertion/deletion in a repetitive region } \\
\text { without a known function. }\end{array}$ \\
\hline BP4 & Bioinformatic analysis predicts benign (protein and splice). \\
\hline BP5 & $\begin{array}{l}\text { Variant found in a case with an alternative molecular } \\
\text { basis for disease. }\end{array}$ \\
\hline
\end{tabular}

A reputable source lists variant as benign (reputable sources are ClinVar at three or four stars): the reputable source must be experts in this disease e.g. a LSDB or a lab that has longstanding experience. "No evidence" means no evidence of their classification details and does not mean no reference at all. Where the classification is present but no details on their individual criteria, it is considered "no evidence". The reference or paper it cites can still be investigated. However, if the detailed criteria is provided, then each evidence must be weighted and this option is no longer viable.

BP7

For synonymous/intronic: splice predictions are benign. At present, if a synonymous/intronic variant is given benign prediction by splice programmes it can be classified as class 2 without the need to investigate conservation.

PVS = very strong evidence of pathogenicity; PS = strong evidence of pathogenicity; ACMG = American College of Medical Genetics and Genomics; $O R=$ odds ratio; $P M=$ moderate evidence of pathogenicity; $P P=$ supporting evidence of pathogenicity; $B A=$ stand-alone evidence of benign impact; $B S=$ strong evidence of benign impact; $B P=$ supporting evidence of benign impact; $L S D B=$ locus-specific database.

Table 2: Criteria used to allocate variants into the five American College of Medical Genetics and Genomics and the Association for Molecular Pathology classes

\begin{tabular}{|c|c|c|}
\hline Class & \multicolumn{2}{|l|}{ Requirement } \\
\hline 1. Benign & \multicolumn{2}{|l|}{ BA $1 \mathrm{MAF} \geq 5 \%$ or $2 \mathrm{BS}$} \\
\hline 2. Likely benign & \multicolumn{2}{|c|}{$\begin{array}{l}1 \mathrm{BS}+1 \mathrm{BP} \text { or } 2 \mathrm{BS} \text {. Only BP7 needed for } \\
\text { synonymous }\end{array}$} \\
\hline 3. Uncertain & \multicolumn{2}{|c|}{$\begin{array}{l}\text { Conflicting information or doesn't meet } \\
\text { criteria of another class }\end{array}$} \\
\hline $\begin{array}{l}\text { 4. Likely } \\
\text { pathogenic }\end{array}$ & $\begin{array}{l}1 \text { PVS + } 1 \text { PM; } \\
1 \text { PS + } 1 \text { PM; } \\
1 \text { PS + } 2 \text { PP }\end{array}$ & $\begin{array}{l}3 \mathrm{PM} \\
2 \mathrm{PM}+2 \mathrm{PP} \\
1 \mathrm{PM}+4 \mathrm{PP}\end{array}$ \\
\hline 5. Pathogenic & $\begin{array}{l}1 \mathrm{PVS}+1 \mathrm{PS} \\
1 \mathrm{PVS}+2 \mathrm{PM} \\
1 \mathrm{PVS}+1 \mathrm{PM}+1 \mathrm{PP} ; \\
1 \mathrm{PVS}+2 \mathrm{PP}\end{array}$ & $\begin{array}{l}2 \mathrm{PS} ; \\
1 \mathrm{PS}+3 \mathrm{PM} ; \\
1 \mathrm{PS}+2 \mathrm{PM}+2 \mathrm{P} \\
1 \mathrm{PS}+1 \mathrm{PM}+4 \mathrm{P}\end{array}$ \\
\hline
\end{tabular}

$B A=$ stand-alone evidence of benign impact $B S=$ strong evidence of benign impact; $B P=$ supporting evidence of benign impact; $P V S=$ very strong evidence of pathogenicity; $P M=$ moderate evidence of pathogenicity; $P S=$ strong evidence of pathogenicity; $P P=$ supporting evidence of pathogenicity.

was used to aid in the interpretation of the variants. As recommended by the ACMG/AMP guidelines, the nomenclature used to describe the variants is based on Human Genome Variation Society guidelines. The reference sequence for this gene was derived from the LRG database. An outline of the approach taken to classify the $30 B R C A 1$ gene variants according to the ACMG/AMP guidelines is shown in Figure 1.

The classification categories were assigned by applying a series of criteria. The criteria were divided into seven attributes based on the ACMG/AMP guidelines. In terms of evidence of pathogenicity these criteria were: very strong (PVS1), strong (PS1-4), moderate (PM1-6) and supporting (PP1-5). In terms of benign impact, the criteria were: stand-alone evidence (BA1), strong evidence (BS1-BS4) and supporting evidence (BP1-BP7) [Table 1]. The outcome of each call for a particular variant was incorporated to give a final score, which was used to determine the final classification from the five-tiered system [Table 2]. 
Table 3: Summary of the patients classified in this study $(\mathrm{N}=30)$

\begin{tabular}{|c|c|c|c|c|c|}
\hline No. & $\begin{array}{l}\text { Nucleotide change } \\
\text { based on HGVS } \\
\text { nomenclature }\end{array}$ & $\begin{array}{l}\text { Amino acid change } \\
\text { based on HGVS } \\
\text { nomenclature }\end{array}$ & $\begin{array}{c}\text { BRCA1 gene } \\
\text { (LRG_292) } \\
\text { exon number }\end{array}$ & $\begin{array}{l}\text { LSDB classification } \\
\text { (BRCA Exchange) }\end{array}$ & $\begin{array}{c}\text { Classification based } \\
\text { on the ACMG/AMP } \\
\text { Guidelines }\end{array}$ \\
\hline 1 & c.66dup & p.(Glu23Argfs"18) & 2 & Pathogenic & class 5 \\
\hline 2 & c.117_118del & p. $($ Cys 39*) & 3 & Pathogenic & class 5 \\
\hline 3 & c. $212+1 G>T$ & p.? & - & Not reviewed & class 5 \\
\hline 4 & c. $212+2 \mathrm{~T}>\mathrm{C}$ & p.? & - & Not reviewed & class 5 \\
\hline 5 & c. $220 \mathrm{C}>\mathrm{T}$ & p. $\left(G \ln 74^{*}\right)$ & 5 & Pathogenic & class 5 \\
\hline 6 & c. $427 \mathrm{G}>\mathrm{T}$ & p.(Glu143") & 6 & Pathogenic & class 5 \\
\hline 7 & c.1018del & p.(Val340*) & 10 & Pathogenic & class 5 \\
\hline 8 & c.1298_1299dup & p.(Ser434Profs*8) & 10 & Not reviewed & class 4 \\
\hline 9 & c.1374del & p.(Asp458Glufs"17) & 10 & Not reviewed & class 5 \\
\hline 10 & c.1953dup & p.(Lys652Glufs"21) & 10 & Pathogenic & class 5 \\
\hline 11 & c.1961dup & p.(Tyr655Valfs*18) & 10 & Pathogenic & class 5 \\
\hline 12 & c.2071del & p. $\left(\operatorname{Arg} 691\right.$ Aspfs*10) $\left.^{*} 10\right)$ & 10 & Pathogenic & class 5 \\
\hline 13 & c.2074del & p.(His692Metfs"9) & 10 & Pathogenic & class 5 \\
\hline 14 & c.2188_2201del & p.(Glu730Thrfs"5) & 10 & Pathogenic & class 5 \\
\hline 15 & c.2280_2281del & p.(Glu761Lysfs*6) & 10 & Not reviewed & class 4 \\
\hline 16 & c. $2447 \mathrm{~A}>\mathrm{G}$ & p.(His816Arg) & 10 & Not reviewed & class 3 \\
\hline 17 & c. 2475 del & p.(Asp825Glufs"21) & 10 & Pathogenic & class 5 \\
\hline 18 & c.2681_2682del & p.(Lys894Thrfs*8) & 10 & Pathogenic & class 5 \\
\hline 19 & c.3143del & p.(Gly1048Valfs"14) & 10 & Pathogenic & class 5 \\
\hline 20 & c.3254_3255dup & p.(Leu1086Aspfs"2) & 10 & Pathogenic & class 5 \\
\hline 21 & c. $3400 \mathrm{G}>\mathrm{T}$ & p.(Glu1134*) & 10 & Pathogenic & class 5 \\
\hline 22 & c. $3607 \mathrm{C}>\mathrm{T}$ & p.(Arg1203*) & 10 & Pathogenic & class 5 \\
\hline 23 & c.3706_3707del & p.(Asn1236Tyrfs"7) & 10 & Pathogenic & class 5 \\
\hline 24 & c. $3718 \mathrm{C}>\mathrm{T}$ & p. $\left(G \ln 1240^{*}\right)$ & 10 & Pathogenic & class 5 \\
\hline 25 & c.3756_3759del & p.(Ser1253Argfs"10) & 10 & Pathogenic & class 5 \\
\hline 26 & c.3759dup & p.(Lys1254*) & 10 & Pathogenic & class 5 \\
\hline 27 & c.4065_4068del & p.(Asn1355Lysfs"10) & 10 & Pathogenic & class 5 \\
\hline 28 & c.4113del & p.(Cys1372Valfs"21) & 11 & Pathogenic & class 5 \\
\hline 29 & c. $4327 \mathrm{C}>\mathrm{T}$ & p. $\left(\operatorname{Arg} 1443^{*}\right)$ & 12 & Pathogenic & class 5 \\
\hline 30 & c. $5152+1 \mathrm{G}>\mathrm{T}$ & p.? & - & Pathogenic & class 5 \\
\hline
\end{tabular}

HGVS = Human Genome Variation Society; BRCA = breast cancer; $L R G=$ locus reference genomic; $L S D B=$ locus-specific database; $A C M G / A M P$ = American College of Medical Genetics and Genomics and the Association for Molecular Pathology.

All diagnostic referrals gave informed consent. The national multi-region ethics committee of New Zealand has ruled that cases of patient management do not require formal ethics committee approval.

\section{Results}

A total of 30 variants were classified in this study, of which 27 were classified as pathogenic (class 5), two variants were classified as likely pathogenic (class 4 ) and one variant was classified as unknown significance 
Table 4: Criteria used to classify breast cancer 1 gene variants

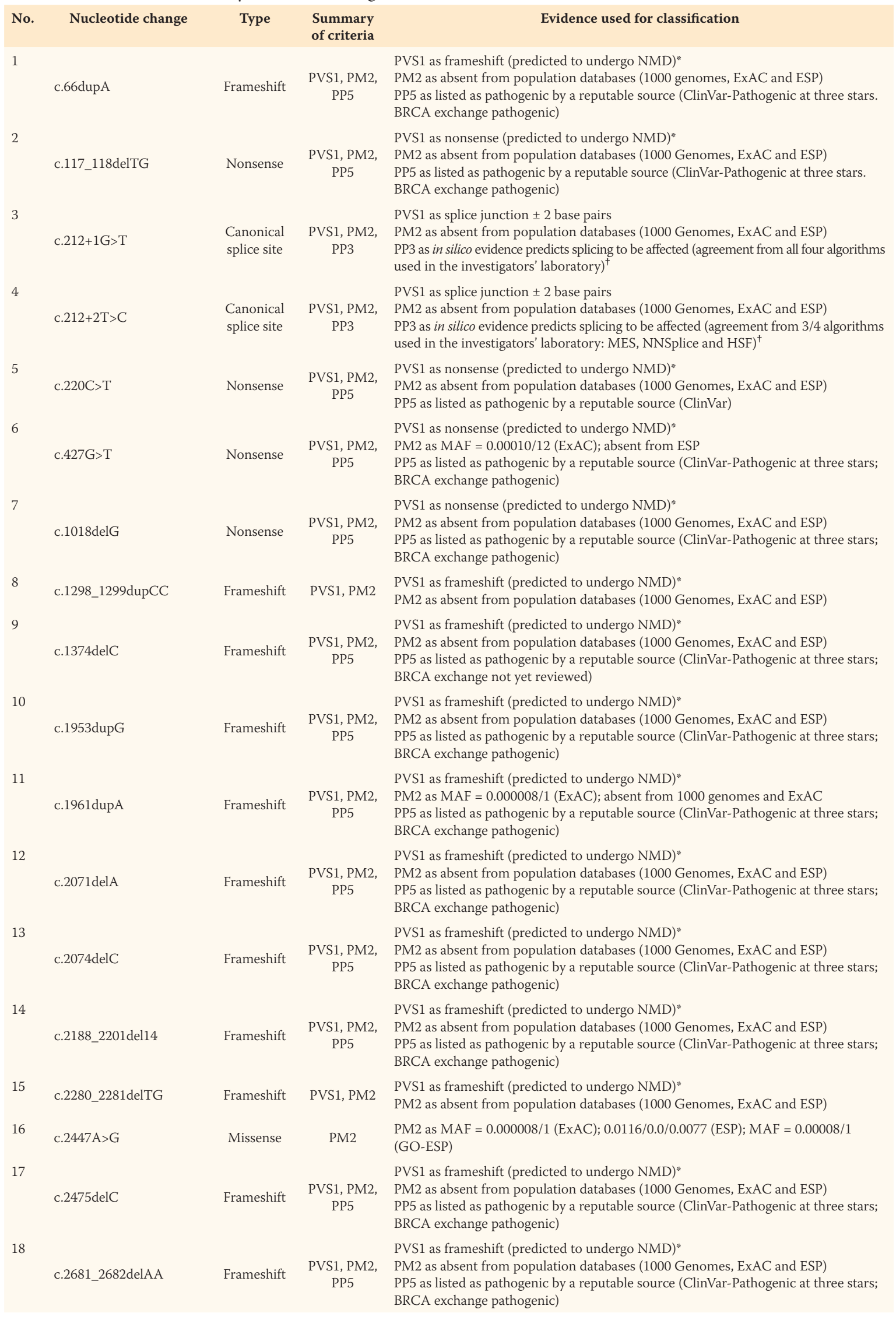

$P V S=$ very strong evidence of pathogenicity; $P M=$ moderate evidence of pathogenicity $P P=$ supporting evidence of pathogenicity; $N M D=n o n s e n s e-$ mediated decay; BRCA = breast cancer "NMD prediction based on the premature termination codon not occurring in the 3' most exon or the 3'-most $50 \mathrm{bp}$ of the penultimate exon; ${ }^{\dagger}$ Using Splice site prediction programme (www.interactive-biosoftware.com/doc/alamut-visual/2.6/splicing.html), MES (http://genes.mit.edu/burgelab/maxent/Xmaxentscan_scoreseq.html), NNSplice (www.fruitfly.org/seq_tools/splice.html) and HSF (www.umd.be/HSF3/). 
Table 4 (cont.): Criteria used to classify breast cancer 1 gene variants

\begin{tabular}{|c|c|c|c|c|}
\hline No. & Nucleotide change & Type & $\begin{array}{l}\text { Summary } \\
\text { of criteria }\end{array}$ & Evidence used for classification \\
\hline 19 & c.3143delG & Frameshift & $\begin{array}{c}\text { PVS1, PM2, } \\
\text { PP5 }\end{array}$ & $\begin{array}{l}\text { PVS1 as frameshift (predicted to undergo NMD)* } \\
\text { PM2 as absent from population databases (1000 Genomes, ExAC and ESP) } \\
\text { PP5 as listed as pathogenic by a reputable source (ClinVar-Pathogenic at three stars; } \\
\text { BRCA exchange pathogenic) }\end{array}$ \\
\hline 20 & c.3254_3255dupGA & Frameshift & $\begin{array}{c}\text { PVS1, PM2, } \\
\text { PP5 }\end{array}$ & $\begin{array}{l}\text { PVS1 as frameshift (predicted to undergo NMD)* } \\
\text { PM2 as absent from population databases (1000 Genomes, ExAC and ESP) } \\
\text { PP5 as listed as pathogenic by a reputable source (ClinVar-Pathogenic at three stars; } \\
\text { BRCA exchange pathogenic) }\end{array}$ \\
\hline 21 & c. $3400 \mathrm{G}>\mathrm{T}$ & Nonsense & $\begin{array}{c}\text { PVS1, PM2, } \\
\text { PP5 }\end{array}$ & $\begin{array}{l}\text { PVS1 as nonsense (predicted to undergo NMD)* } \\
\text { PM2 as absent from population databases ( } 1000 \text { Genomes, ExAC and ESP) } \\
\text { PP5 as listed as pathogenic by a reputable source (ClinVar-Pathogenic at three stars; } \\
\text { BRCA exchange pathogenic) }\end{array}$ \\
\hline 22 & c. $3607 \mathrm{C}>\mathrm{T}$ & Nonsense & $\begin{array}{c}\text { PVS1, PM2, } \\
\text { PP5 }\end{array}$ & $\begin{array}{l}\text { PVS1 as nonsense (predicted to undergo NMD)* } \\
\text { PM2 as MAF }=0.00008 / 1 \text { (GO-ESP), 0.0/0.0227/0.0077. Absent from } 1000 \text { Genomes } \\
\text { and ExAC } \\
\text { PP5 as listed as pathogenic by a reputable source (ClinVar-Pathogenic at three stars; } \\
\text { BRCA exchange pathogenic) }\end{array}$ \\
\hline 23 & c.3706_3707delAA & Frameshift & $\begin{array}{c}\text { PVS1, PM2, } \\
\text { PP5 }\end{array}$ & $\begin{array}{l}\text { PVS1 as frameshift (predicted to undergo NMD)* } \\
\text { PM2 as absent from population databases (1000 Genomes, ExAC and ESP) } \\
\text { PP5 as listed as pathogenic by a reputable source (ClinVar-Pathogenic at three stars; } \\
\text { BRCA exchange pathogenic) }\end{array}$ \\
\hline 24 & c. $3718 \mathrm{C}>\mathrm{T}$ & Nonsense & $\begin{array}{c}\text { PVS1, PM2, } \\
\text { PP5 }\end{array}$ & $\begin{array}{l}\text { PVS1 as nonsense (predicted to undergo NMD)* } \\
\text { PM2 as absent from population databases (1000 Genomes, ExAC and ESP) } \\
\text { PP5 as listed as pathogenic by a reputable source (ClinVar-Pathogenic at three stars; } \\
\text { BRCA exchange pathogenic) }\end{array}$ \\
\hline 25 & c.3756_3759delGTCT & Frameshift & $\begin{array}{l}\text { PVS1, PS4, } \\
\text { PM2, PP5 }\end{array}$ & $\begin{array}{l}\text { PVS1 as frameshift (predicted to undergo NMD)* } \\
\text { PS4 as this variant has been reported in multiple patients with breast and ovarian cancer } \\
\text { PM2 as MAF }=0.00002 / 3 \text { (ExAC), MAF }=0.0210 / 263 \text { (GO-ESP), } 2.1934 / 1.9231 / 2.1013 \text { (ESP) } \\
\text { PP5 as listed as pathogenic by a reputable source (ClinVar-Pathogenic at three stars; } \\
\text { BRCA exchange pathogenic) }\end{array}$ \\
\hline 26 & c.3759dupT & Nonsense & $\begin{array}{c}\text { PVS1, PM2, } \\
\text { PP5 }\end{array}$ & $\begin{array}{l}\text { PVS1 as nonsense (predicted to undergo NMD)* } \\
\text { PM2 as absent from population databases ( } 1000 \text { Genomes, ExAC and ESP) } \\
\text { PP5 as listed as pathogenic by a reputable source (ClinVar-Pathogenic at three stars; } \\
\text { BRCA exchange pathogenic) }\end{array}$ \\
\hline 27 & c.4065_4068delTCAA & Frameshift & $\begin{array}{l}\text { PVS1, PS4, } \\
\text { PM2, PP5 }\end{array}$ & $\begin{array}{l}\text { PVS1 as frameshift (predicted to undergo NMD)* } \\
\text { PS4 as this variant is reported in multiple patients with breast and ovarian cancer } \\
\text { PM2 as MAF }=0.00002 / 2 \text { (ExAC). Absent from population databases ( } 1000 \text { Genomes and ESP) } \\
\text { PP5 as listed as pathogenic by a reputable source (ClinVar-Pathogenic at three stars; } \\
\text { BRCA exchange pathogenic) }\end{array}$ \\
\hline 28 & c.4113delG & Frameshift & $\begin{array}{c}\text { PVS1, PM2, } \\
\text { PP5 }\end{array}$ & $\begin{array}{l}\text { PVS1 as frameshift (predicted to undergo NMD)* } \\
\text { PM2 as absent from population databases (1000 Genomes, ExAC and ESP) } \\
\text { PP5 as listed as pathogenic by a reputable source (ClinVar-Pathogenic at three stars; } \\
\text { BRCA exchange pathogenic) }\end{array}$ \\
\hline 29 & c. $4327 \mathrm{C}>\mathrm{T}$ & Nonsense & $\begin{array}{l}\text { PVS1, PS4, } \\
\text { PM2, PP5 }\end{array}$ & $\begin{array}{l}\text { PVS1 as nonsense (predicted to undergo NMD)* } \\
\text { PS4 as this variant is reported to be a common cause of breast and ovarian cancer in the } \\
\text { French Canandian population but also observed in individuals from other ethnicities. } \\
\text { PM2 as MAF }=0.00002 / 3 \text { (ExAC), absent from ESP } \\
\text { PP5 as listed as pathogenic by a reputable source (ClinVar-Pathogenic at three stars; } \\
\text { BRCA exchange pathogenic) }\end{array}$ \\
\hline 30 & c. $5152+1 \mathrm{G}>\mathrm{T}$ & $\begin{array}{l}\text { Canonical } \\
\text { splice site }\end{array}$ & $\begin{array}{l}\text { PVS1, PM2, } \\
\text { PP3, PP5 }\end{array}$ & $\begin{array}{l}\text { PVS1 as splice junction } \pm 2 \text { base pairs } \\
\text { PM2 as absent from population databases (1000 Genomes, ExAC and ESP) } \\
\text { PP3 as in silico evidence predicts splicing to be affected (agreement from all four } \\
\text { algorithms used in the investigators' laboratory) } \\
\text { PP5 as listed as pathogenic by a reputable source (ClinVar-Pathogenic at three stars; } \\
\text { BRCA exchange pathogenic) }\end{array}$ \\
\hline
\end{tabular}

$P V S=$ very strong evidence of pathogenicity; $P M=$ moderate evidence of pathogenicity; $P P=$ supporting evidence of pathogenicity; $N M D=n o n s e n s e-$ mediated decay; BRCA = breast cancer 'NMD prediction based on the premature termination codon not occurring in the 3' most exon or the 3'-most $50 \mathrm{bp}$ of the penultimate exon; ${ }^{\dagger}$ Using Splice site prediction programme (www.interactive-biosoftware.com/doc/alamut-visual/2.6/splicing.html), MES (http://genes.mit.edu/burgelab/maxent/Xmaxentscan_scoreseq.html), NNSplice(www.fruitfly.org/seq_tools/splice.html) and HSF (www.umd.be/HSF3/).

(class 3) [Table 3]. The details of evidence used to classify each variant are shown in Table 4.

Other than the missense mutation (c.2447A $>\mathrm{G}$ ), the remaining variants were assigned PVS1. The rationale for this classification was that all of these variants were either nonsense (variants 2, 5-7, 21, 22, 24, 26 and 29), frameshift (variants 1, 8-15, 17-
20, 23, 25, 27 and 28) or canonical \pm 1 or 2 splice site (variants 3, 4 and 30) variants. The ACMG/AMP guidelines assign these variants as PVS1 as they can often be assumed to disrupt gene function by leading to complete absence of the gene product by lack of transcription or nonsense-mediated decay (NMD) of the altered transcript. ${ }^{13}$ Variants predicted not to 
Table 5: Summary of the implications and consequences of variant classifications

\begin{tabular}{|c|c|c|c|c|}
\hline Class & $\begin{array}{l}\text { Further } \\
\text { revision }\end{array}$ & $\begin{array}{l}\text { Reported } \\
\text { as }\end{array}$ & $\begin{array}{l}\text { Predictive } \\
\text { testing }\end{array}$ & $\begin{array}{c}\text { Familial } \\
\text { segregation } \\
\text { analysis }\end{array}$ \\
\hline 1 & No & $\begin{array}{l}\text { Not } \\
\text { reported }\end{array}$ & No & No \\
\hline 2 & $\begin{array}{c}\mathrm{Bi}- \\
\text { annually }\end{array}$ & $\begin{array}{c}\text { Not } \\
\text { reported }\end{array}$ & No & No \\
\hline 3 & Annual & $\begin{array}{l}\text { Uncertain } \\
\text { clinical } \\
\text { significance }\end{array}$ & No & Yes \\
\hline 4 & Annual & $\begin{array}{c}\text { Likely } \\
\text { pathogenic }\end{array}$ & $\begin{array}{c}\text { Yes } \\
\text { (counselling } \\
\text { required) }\end{array}$ & No \\
\hline 5 & No & Pathogenic & $\begin{array}{l}\text { Yes } \\
\text { (counselling } \\
\text { required) }\end{array}$ & No \\
\hline
\end{tabular}

trigger NMD have been defined as those that lead to a stop codon 50 nucleotides before or within the last exon. ${ }^{15}$ It is also suggested that variants in close proximity to the translation initiation codon can also escape NMD due to downstream reinitiation. ${ }^{16}$ In this study, the most 5' variant was c.66dupA, which is in exon 2, 66 nucleotides downstream from the first nucleotide; it is therefore not considered very close to the translation initiation codon. The most 3' exon with a variant in this gene was in exon 17 . Given that exon 18-23 contain 436 nucleotides, it was concluded that none of the current detected variants would prevent NMD from occurring. Therefore, PVS1 was assigned to each frameshift and nonsense variant. For the three splice site variants (variants 3, 4 and 30), Alamut Visual software (Interactive Biosoftware, Rouen, France) predicted that skipping of exons 4 and 17 was very likely. Both exons 4 and 17 are 78 base pairs or 26 amino acids long. Skipping of these exons would lead to an in-frame deletion of this protein, which would normally lead to assigning criterion PM4. However, exons 4 and 17 encode part of the Really Interesting New Gene and BRCA1 C-Terminus domains, which are essential for the proteins role as a tumour suppressor. ${ }^{17}$ Therefore, the investigators decided that they had sufficient evidence to assign criterion PVS1 to these three variants.

Variant frequencies were assessed in population databases including 1000 genomes, ExAC and ESP. Variants were assigned the PM2 criterion if the variant was absent or had an extremely low frequency in population databases. The databases examined for each variant are described in Table 4. In the investigators' laboratory, ClinVar was considered a reputable disease database and the PP5 criterion was assigned to any variant with a pathogenic interpretation in ClinVar that had expert panel review status. Variants designated PP3 were those in which in silico data had been obtained
[Table 4]. The PS4 criterion can be assigned to variants with an increased prevalence in affected individuals compared to the controls. In this study, PS4-assigned variants were those that had been reported to be seen in multiple patients with breast and ovarian cancer.

The investigators' variant classification approach led to one variant being classified as class 3; two as class 4 and 27 as class 5 . In the case of the class 3 variant (variant 16), it satisfied criterion PM2 as it was present at an extremely low frequency in population databases. This variant had conflicting evidence for pathogenicity in ClinVar as did in silico prediction software. In addition, there was an absence of publications describing this variant. The two class 4 variants (variants 8 and 15) were classified as likely pathogenic as there was a lack of supporting ClinVar evidence and no literature was found describing these variants. Table 3 provides a summary of the classification together with those present in the BRCA Exchange. The classification of variants in the BRCA Exchange were concordant with the ACMG/AMPbased classifications.

\section{Discussion}

The purpose of this study was to classify 30 variants detected in the BRCA1 gene according to the ACMG/ AMP guidelines. The variants described in the current study were detected prior to the implementation of these guidelines, and as a result they had not been curated consistently. For the initial classification, a variety of online resources had been used such as: the BIC database; their ClinVar status and their International Agency for Research on Cancer class. Included in the study were seventeen frameshift, nine nonsense, three intronic variants and a single missense variant.

The classification of the variants was weighted heavily on the type of variant, the frequency of the variant and the ClinVar classification. BRCA1 exhibits an autosomal dominant pattern of inheritance. ${ }^{18}$ Therefore, a heterozygous variant has potential to cause disease. The majority of clinically significant deleterious mutations within the BRCA1 and BRCA2 genes have been reported to be protein-truncating mutations, while a small number are missense mutations. ${ }^{5}$ The majority of variants in this study were either frameshift or nonsense mutations. The investigators' interpretation of the ACMG/AMP guidelines enabled the majority (97\%) of the variants to be assigned PVS1.

The criteria were sufficient to enable all but one of the variants to be classified as either 'likely pathogenic' or 'pathogenic', thus providing an informative result for clinicians who could focus on the clinical management 
of patients with these variants in the future. Use of the current methodology based on ACMG/AMP variant classification guidelines gave final calls with a high level of concordance to well-curated locus-specific databases. All 24 variants in this study that were listed as pathogenic by the BRCA Exchange were also classified as class 5 pathogenic variants.

Recent evaluations of the ACMG/AMP guidelines have been published. ${ }^{19,20}$ One study examined the classification findings across nine laboratories in the USA. ${ }^{19}$ Although these findings showed that the use of the ACMG/AMP guidelines did not initially improve interlaboratory concordance, they did provide a common framework to facilitate resolution of the differences when discussed subsequently. ${ }^{19}$ In addition, Maxwell et al. classified 1,640 variants and summarised that their findings supported the clinical utility of ACMG/ AMP variant-classification guidelines..$^{20}$ Outside of the USA, other countries are adopting these guidelines. In November 2016, a consensus statement was issued by the Association for Clinical Genomic Science (ACGS). It recommended use of the ACMG/AMP guidelines for germline variant classification and interpretation in UK diagnostic genetic laboratories performing testing of rare disease and familial cancers. ${ }^{21}$ This development highlights that there is an international effort in place to standardise variant interpretation. These guidelines were recognised to provide a starting point for further refinements and extensions in the future. $^{22}$ The Sequence Variant Interpretation (SVI) Working Group has begun this process, taking on the task of improving the current ACMG/AMP recommendations in order to develop quantitative approaches to variant interpretation. As a result of this, the ACGS published best practice guidelines for variant classification in 2018. ${ }^{21}$

According to the ACMG/AMP guidelines, the PVS1 criterion provides a very strong level of confidence in assigning pathogenicity; however, there are certain caveats to this criterion. The factors to take into consideration when assigning PVS1 include: ensuring that loss of function is a known disease mechanism; using caution when interpreting loss of function variants at the extreme 3' end of a gene; attention to splice variants that are predicted to lead to exon skipping but leave the remainder of the protein intact; the presence of multiple transcripts and assuming that a null variant will lead to disease if found in an exon where no other pathogenic variants have been described. Due to concerns that inappropriate use of this criterion may have a significant impact on a patient's well-being, the SVI working group has produced recommendations for interpreting the loss of function PVS1 ACMG/AMP variant criterion. ${ }^{23}$
These recommendations provide a detailed description of the types of variants that can be assigned this classification, as well as a decision tree to aid in variant interpretation.

The PP5 criterion was frequently used in the current study. This criterion requires that a reputable source lists the variant as pathogenic but doesn't state how the classification was determined. This criterion is appropriate when information is obtained from a clinical laboratory that has long-standing expertise in the disease area. Within the current laboratory, it was thought appropriate to apply PP5 when there was a ClinVar review with three stars supporting pathogenicity. The SVI working group suggested that PP5 (along with its benign equivalent, BP6) be removed from the criteria. This is due to the fact that ClinVar has become so successful that submissions with 'assertion criteria provided' account for the majority of cases uploaded and that sufficient primary evidence is now available. ${ }^{22}$

The PP3 criterion was used in this study alongside PVS1 for intronic variants. Although not stated in the ACMG/AMP guidelines, the SVI working group has suggested avoiding using PP3 together with PVS1 as the evidence is based on the same set of data and has the potential to lead to errors in classification. ${ }^{23}$ If that suggestion had been followed in the current study, two of the three canonical splice site variants (variants 3 and 4) would be reclassified as class 4 (from class 5) but the remaining variant (variant 30) would remain a class 5 .

Table 5 summarises the implications to the laboratory and to the clinic regarding the consequences of variant classification. Having the ACMG/AMP guidelines in place allows the laboratory to assign an appropriate frequency of revisions.

As discussed above, refinement of the ACMG/ AMP guidelines has already began and will continue to evolve over time. Within the investigators' laboratory, the development of a work-up document for internal use following the ACMG/AMP guidelines has enabled a more systematic approach to variant interpretation and proved a useful resource in achieving rigour regarding variant classification. The refinement of these guidelines will continue to improve the interpretation of variants, ultimately leading to an improvement in patient care.

For the classification of variants in this study the following criteria were not used: PS2 (de novo-paternity confirmed); PM6 (assumed de novo, but without confirmation); PP1 (co-segregation with disease); BS4 (lack of segregation in affected members) and PP4 (patient's phenotype or family history is highly specific for a disease with a single genetic aetiology). Information 
was not available regarding family history, the inheritance of the variants or the patients' clinical status. Although the majority of the variants described here were classified as pathogenic without this additional information, this is not always going to be the case and the availability of as much information as possible is essential to provide accurate variant classification.

The advantage of an approach that adheres to international guidelines is the acknowledgement that variant classification requires objectivity but recognising that best practice is aspirational. While the BCRA Exchange classifications were used as a benchmark, recent work of Cusin et al. provides a salutary lesson. ${ }^{24}$ These authors highlight the importance of including information regarding the molecular and cellular impacts of variants, which need to be retrieved in a computationally accessible format. ${ }^{24}$ This is especially so for class 3 variants that currently suffer from a paucity of functional data, as well as limited clinical impact data due to the logistic challenges of performing familial segregation analysis. Diagnostic laboratories should play a larger role in addressing the latter, while research laboratories should address the former.

\section{Conclusion}

The use of ACMG/AMP guidelines for the classification of DNA variants allows a diagnostic laboratory to benchmark their classifications against other laboratories so as to achieve consistency in outcomes. This benchmarking also enables clinicians to have confidence in the veracity of diagnostic reports and provides a transparent process that is subject to objective evidence.

\section{CONFLICT OF INTEREST}

The authors declare no conflicts of interest.

\section{FUNDING}

No funding was received for this study.

\section{References}

1. Ferlay J, Hery C, Autier P, Sankaranarayanan R. Global Burden of Breast Cancer. In: Li, C., Ed., Breast Cancer Epidemiology, Springer, New York. 2010; 1-19.

2. Gayther SA, Warren W, Mazoyer S, Russell PA, Harrington PA, Chiano $\mathrm{M}$, et al. Germline mutations of the BRCA1 gene in breast and ovarian cancer families provide evidence for a genotype-phenotype correlation. Nat Genet 1995; 11:428-33. https://doi.org/10.1038/ng1295-428.

3. Bergthorsson JT, Ejlertsen B, Olsen JH, Borg A, Nielsen KV, Barkardottir RB, et al. BRCA1 and BRCA2 mutation status and cancer family history of Danish women affected with multifocal or bilateral breast cancer at a young age. J Med Genet 2001; 38:361-8. https://doi.org/10.1136/jmg.38.6.361.
4. Wooster R, Neuhausen SL, Mangion J, Quirk Y, Ford D, Collins N, et al. Localization of a breast cancer susceptibility gene, BRCA2, to chromosome 13q12-13. Science 1994; 265:2088-90. https://doi.org/10.1126/science.8091231.

5. Balmaña J, Diez O, Rubio I, Castiglione M; ESMO Guidelines Working Group. BRCA in breast cancer: ESMO Clinical Practice Guidelines. Ann Oncol 2010; 21 Suppl 5:v20-2. https://doi. org/10.1093/annonc/mdq161.

6. Petrucelli N, Daly MB, Pal T. BRCA1- and BRCA2-Associated Hereditary Breast and Ovarian Cancer. In: Adam MP, Ardinger HH, Pagon RA, Wallace SE, Bean LJH, Stephens K, Eds. GeneReviews ${ }^{\oplus}$. Seattle, USA: University of Washington, Seattle, 1993-2019. https://www.ncbi.nlm.nih.gov/books/NBK1247/.

7. McVeigh TP, Cody N, Carroll C, Duff M, Farrell M, Bradley L, et al. Recurrent large genomic rearrangements in BRCA1 and BRCA2 in an Irish case series. Cancer Genet 2017; 214-15:1-8. https://doi.org/10.1016/j.cancergen.2017.02.001.

8. Cargill CF. Why standardization efforts fail. J Electronic Publishing 2011; 14. http://doi.org/10.3998/3336451.0014.103.

9. Hoffman-Andrews L. The known unknown: The challenges of genetic variants of uncertain significance in clinical practice. J Law Biosci 2018; 4:648-57. https://doi.org/10.1093/jlb/lsx038.

10. Antonarakis SE. Recommendations for a nomenclature system for human gene mutations. Nomenclature Working Group. Hum Mutat 1998; 11:1-3. https://doi.org/10.1002/(SICI)10981004(1998)11:1<1::AID-HUMU1>3.0.CO;2-O.

11. den Dunnen JT, Antonarakis SE. Mutation nomenclature extensions and suggestions to describe complex mutations: A discussion. Hum Mutat 2000; 15:7-12. https://doi.org/10.1002/ (SICI)1098-1004(200001)15:1<7::AID-HUMU4>3.0.CO;2-N.

12. Wildeman M, van Ophuizen E, den Dunnen JT, Taschner PE. Improving sequence variant descriptions in mutation databases and literature using the Mutalyzer sequence variation nomenclature checker. Hum Mutat 2008; 29:6-13. https://doi.org/10.10 02/humu.20654.

13. Richards S, Aziz N, Bale S, Bick D, Das S, Gastier-Foster J, et al. Standards and guidelines for the interpretation of sequence variants: A joint consensus recommendation of the American College of Medical Genetics and Genomics and the Association for Molecular Pathology. Genet Med 2015; 17:405-24. https://doi.org/10.1038/gim.2015.30.

14. Roy S, Coldren C, Karunamurthy A, Kip NS, Klee EW, Lincoln SE, et al. Standards and guidelines for validating Next-Generation Sequencing bioinformatics pipelines: A joint recommendation of the Association for Molecular Pathology and the College of American Pathologists. J Mol Diagn 2018; 20:4-27. https://doi.org/10.1016/j.jmoldx.2017.11.003.

15. Palacios IM. Nonsense-mediated mRNA decay: From mechanistic insights to impacts on human health. Brief Funct Genomics 2013; 12:25-36. https://doi.org/10.1093/bfgp/els051.

16. Perrin-Vidoz L, Sinilnikova OM, Stoppa-Lyonnet D, Lenoir GM, Mazoyer S. The nonsense-mediated mRNA decay pathway triggers degradation of most BRCA1 mRNAs bearing premature termination codons. Hum Mol Genet 2002; 11:2805-14. https://doi.org/10.1093/hmg/11.23.2805.

17. Findlay GM, Daza RM, Martin B, Zhang MD, Leith AP, Gasperini M, et al. Accurate classification of BRCA1 variants with saturation genome editing. Nature 2018; 562:217-22. https://doi.org/10.1038/s41586-018-0461-z.

18. Hodgson S. Mechanisms of inherited cancer susceptibility. J Zhejiang Univ Sci B 2008; 9:1-4. https://doi.org/10.1631/jzus. B073001.

19. Amendola LM, Jarvik GP, Leo MC, McLaughlin HM, Akkari Y, Amaral MD, et al. Performance of ACMG-AMP variantinterpretation guidelines among nine laboratories in the Clinical Sequencing Exploratory Research Consortium. Am J Hum Genet 2016; 99:247. https://doi.org/10.1016/j.ajhg.2016.06.001. 
20. Maxwell KN, Hart SN, Vijai J, Schrader KA, Slavin TP, Thomas T, et al. Evaluation of ACMG-guideline-based variant classification of cancer susceptibility and non-cancer-associated genes in families affected by breast cancer. Am J Hum Genet 2016; 98:801-17. https://doi.org/10.1016/j.ajhg.2016.02.024.

21. Ellard S, Baple EL, Owens M, Eccles DM, Turnbull C, Abbs S, et al. ACGS best practice guidelines for variant classification 2018. Association for Clinical Genomic Science. https://www. acgs.uk.com/quality/best-practice-guidelines/.

22. Biesecker LG, Harrison SM. The ACMG/AMP reputable source criteria for the interpretation of sequence variants. Genet Med 2018; 20:1687-8. https://doi.org/10.1038/gim.2018.42.
23. Abou Tayoun AN, Pesaran T, DiStefano MT, Oza A, Rehm HL, Biesecker LG, et al. Recommendations for interpreting the loss of function PVS1 ACMG/AMP variant criterion. Hum Mutat 2018; 39:1517-24. https://doi.org/10.1002/humu.23626.

24. Cusin I, Teixeira D, Zahn-Zabal M, Rech de Laval V, Gleizes A, Viasolo V, et al. A new bioinformatics tool to help assess the significance of BRCA1 variants. Hum Genomics 2018; 12:36. https://doi.org/10.1186/s40246-018-0168-0. 